\title{
La voz de nuestra América: el \\ sumak kawsay y la crítica intercultural al desarrollo
}

[Artículos de investigación]

Jaime Javier Villanueva Barreto*

Recibido: 7 de noviembre de 2020

Aceptado: o9 de febrero de 2021

Citar como:

Villanueva, J. (2021). La voz de nuestra América: el sumak kawsay y la crítica intercultural al desarrollo. Campos en Ciencias Sociales, 9(1).

https://doi.org/10.15332/25006681.6925

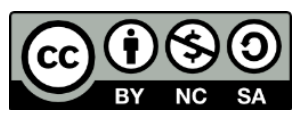

\section{Resumen}

Este artículo explora los aspectos filosóficos del sumak kawsay, entendido como buen vivir, es decir, como una apuesta vital y ancestral que se presenta en el orden civilizatorio andino, haciendo énfasis en su poder crítico frente al modelo hegemónico propio de la sociedad neoliberal. Inicialmente, el término se vincula con su propia significación lingüística, para extraer de ahí su sentido. Luego, se intenta una conceptualización del buen vivir, vinculándolo con su aspecto crítico, y, finalmente, se plantea el buen vivir desde la perspectiva de la filosofía indígena y del debate que se abre ahí en relación con la naturaleza.

Palabras clave: sumak kawsay, naturaleza, desarrollo, filosofía andina.

* Universidad Nacional Mayor de San Marcos. Correo electrónico:

jvillanuevabarreto@gmail.com; ORCID: https://orcid.org/0000-0002-1168-8379

Campos en Ciencias Sociales

ISSN: 2339-3688 | e-ISSN: 2500-6681 | DOI: https://doi.org/10.15332/25394363

Vol. 9 N.o 1 | enero-junio de 2021 


\section{The Voice of Our America: The Sumak Kawsay and the Intercultural Critique of Development}

\section{Abstract}

This article explores the philosophical aspects of Sumak Kawsay, understood as "good living", that is, as a vital and ancestral commitment that is presented in the Andean civilizational order, emphasizing its critical potential against the hegemonic model of neoliberal society. At first, the term is linked to its linguistic meaning, to extract from there its sense; then, a conceptualization of "good living" is linked to its critical aspect; and finally, "good living" is presented from the perspective of indigenous philosophy and the debate that opens up there in relation to nature.

Keywords: Sumak Kawsay, nature, development, Andean philosophy.

\section{El sentido del sumak kawsay en las lenguas andinas}

Para poder abordar el concepto de sumak kawsay, es necesario, en una primera instancia, desarrollar y comprender lo que este vocablo significa en las lenguas andinas. Tal concepto posee una variada dicción en la región andina de América Latina. Esta diversidad en la dicción no solo es resultado de las diferentes lenguas andinas, sino que también está atada a las condiciones regionales y temáticas.

Para ejemplificar lo anterior revisemos las expresiones sumak kawsay y suma qamaña. La primera es quichua ecuatoriano y expresa la idea de una vida no mejor, no mejor que la de otros ni en un continuo desvivir por mejorarla, sino simplemente buena. La segunda viene del aimara boliviano e introduce el elemento comunitario, por lo que tal vez se podría traducir como "buen vivir", la sociedad buena para todos en suficiente armonía interna. Ambos conceptos expresan la visión de los marginados por la historia, los pueblos y sociedades indígenas, que se plantearon el reto de construir otra sociedad sustentada en una convivencia ciudadana en 
diversidad y armonía con la naturaleza, a partir del reconocimiento de los diversos valores culturales existentes en nuestro continente y en el mundo. El quechua y el aimara son dos de los idiomas prehispánicos más utilizados en las regiones andinas e incluso siguen siendo hablados en la actualidad por millones de personas. Si bien otras lenguas indígenas en América Latina tienen también una relación con los términos usados por las comunidades andinas, son los conceptos que proceden del quechua o quichwa y del aimara los que tienen una mayor relevancia.

$\mathrm{Al}$ realizar un análisis lingüístico de los conceptos ya mencionados, la traducción al español se enfrenta con inmensas complicaciones. Se debe resaltar que en la trascripción de los idiomas orales al lenguaje escrito y fonético latino hay una gran variación debido a la lógica del lenguaje. Tales variantes se han intentado diferenciar claramente en los últimos años por las academias de las lenguas regionales. Con ello se evidencia que hay importantes diferencias, por ejemplo, entre el quechua peruano, el quichwa ecuatoriano y el quechua boliviano. Sin embargo, las diferencias lingüísticas entre el aimara de países como Bolivia y Perú no son menores que las del quechua.

En las lenguas andinas, el término buen vivir se puede entender de la siguiente forma:

El término en aimara [...] se representa como suma qamaña, suma kamaña o suma jakaña. El adjetivo suma que es común al aimara y al quechua [...] significa 'bueno', 'agradable', 'armonioso' y 'sabroso' (en relación a los alimentos). Los conceptos qamaña, kamaña y jakaña pueden ser empleados, debido al sufijo ña, tanto como verbos (en su forma infinitiva), como sustantivos (verbo sustantivado). La raíz qama o qamasa refiere a la 'energía' y la 'fuerza'; se emplea con frecuencia en la región andina refiriendo a uno de los distintos aspectos espirituales ('almas') de los seres humanos. La raíz kama significa 'crear', 'organizar': y jaka 
significa 'vivir' en el sentido de la vida biológica de 'estar vivo'.

(Estermann, 2011b, p. 2) ${ }^{1}$

Mientras tanto, en el idioma quechua también se pueden apreciar variaciones del término buen vivir según el país de donde provenga:

El término en el idioma quechua es allin kawsay, con las variaciones regionales allin kausay, sumaq kawsay (Perú), sumaj kausay, sumaj kawsay (Bolivia) o sumak kawsay (Ecuador). Aquí, el adjetivo (sumaj/q; allin) varía según el contexto y el juego de lenguaje: allín tiene un significado general en el sentido de 'bueno' [...]. Sumaj/q en cambio, tiene el sentido de 'excelente', 'maravilloso', 'sabroso' (para los alimentos), o de 'excepcional' y 'elevado', por lo que tiene una función más bien superlativa. A diferencia del aimara, en el quechua sólo se utiliza como verbo complemento kawsay (o kausay/kausai), pero se da también en la doble función como verbo (infinitivo) y sustantivo (verso sustantivado).

(Estermann, 2011b, p. 3)

Aparte de las diferencias que se pueden encontrar en las mismas lenguas indígenas, en la traducción de tales conceptos existen, del mismo modo, dificultades. Lo que sucede es que al intentar traducir dicho concepto al español u otras lenguas indoeuropeas se da el problema de la sintaxis, que en el caso de las lenguas indígenas está centrada en el verbo, mientras que en las lenguas indoeuropeas la sintaxis está más bien centrada en el sustantivo.

Es así que los términos utilizados en las lenguas indígenas como el quechua y aimara debe ser traducido de un modo determinado. Con ello es que la traducción al castellano de "vida buena” se puede dar de la siguiente

\footnotetext{
${ }^{1}$ Una diferenciación que es considerada necesaria por muchos lingüistas es la referente a qamaña y jackaña. Ello se debe a que, entre los posibles significados de jakaña, el concepto se puede traducir como "'útero" o "placenta"; por lo que diversos lingüistas creen que el término de qamaña debe ser utilizado como la forma masculina del buen vivir, mientras que jakaña sería la forma femenina de ese mismo concepto.
}

Campos en Ciencias Sociales

ISSN: 2339-3688 | e-ISSN: 2500-6681 | DOI: https://doi.org/10.15332/25394363

Vol. 9 N.o 1 | enero-junio de 2021 
manera: "buen vivir", "vida buena" y "buena vida". Sin embargo, cualquier traducción en términos de "vida buena" pierde el impulso que se le otorga en el significado original andino, pues podríamos confundirlo con el ya establecido por la tradición filosófica desde Aristóteles. Los términos sumak kawsay y sumak qamaña no hacen referencia a una "vida buena" y ni siquiera a una "vida de bienestar", al contrario, refieren a un buen vivir en el sentido más vital de vivir bien, es decir, en completa armonía con los otros y con la naturaleza.

Compromete la vida del sujeto y su relación con su entorno natural, con su medio, lo que comprende tanto a los otros sujetos como a las plantas y animales. Buen vivir, desde esta perspectiva, hace referencia entonces no a una buena vida, sino a un bien "vivir", es decir, "tener" una vida buena. Lo que implica el cuidado de los otros y de la naturaleza sin los cuales nuestra propia vida no sería posible.

Hay que aclarar que la noción del buen vivir, aunque anclada en cosmovisiones relacionales, es también un proyecto político que surge en tensión con nociones desarrollistas de la 'buena vida', aun dentro de las mismas comunidades indígenas y afro de América Latina, causando conflicto en ellas. Es importante verlas en el flujo histórico del poder y los significados para entender cómo se proyectan política y culturalmente más allá de formas liberales y antropocéntricas.

La noción de sumak kawsay (o sumaj qamaña, en aimara), forma parte del discurso político de los movimientos indígenas del continente, en especial del movimiento indígena de Ecuador y de Bolivia, y, en tal virtud, forma parte de su proyecto político e histórico. El sumak kawsay, de su parte, es la crítica más fuerte y radical que se ha realizado a los paradigmas de crecimiento económico por la vía de los mercados y a la noción teleológica del desarrollo como posibilidad histórica. (Prada, 2013, p. 44) 
En ese sentido, el buen vivir implica algo distinto a la concepción de "sociedad de bienestar" que se maneja en occidente. Sin embargo, esto no significa la renuncia a la modernización de la sociedad. Vivimos en un proceso histórico y de escalas tan universales, que ya resulta imposible que se puedan negar los valiosos aportes del pensamiento de la humanidad; como veremos más adelante, están también pueden estar en sintonía con la construcción de un mundo armónico como se deriva de la filosofía del buen vivir. Por eso mismo, una de las tareas fundamentales recae en el diálogo permanente y constructivo de saberes y conocimientos ancestrales con el pensamiento occidental, en un proceso de continuada descolonización de la sociedad. El buen vivir, no sólo como propuesta política, sino como filosofía de vida todavía en construcción, cuestiona el concepto occidental de bienestar.

\section{Hacia una conceptualización del buen vivir y la crítica al desarrollo}

El concepto del buen vivir implica una reinterpretación de los principales valores y principios que sustentan la cosmovisión indígena, en la cual hay un equilibrio entre todos los seres del mundo. Ello incluye a los humanos, animales, plantas, astros, divinidades y espíritus. Cada ser es importante y merece ser respetado, ninguno debe ser tratado de modo utilitario o instrumento. Es una visión del mundo que se centra en la relación entre el hombre y su entorno social y natural ${ }^{2}$. Según Mujica, "el contacto con la

\footnotetext{
2 Véanse los siguiente textos relacionado al tema: Derechos de la naturaleza: el futuro es ahora (Acosta, 2009); El buen vivir: una vía para el desarrollo (Acosta y Esperanza Martínez, 2009); La naturaleza con derechos: de la filosofía a la política (Acosta y Esperanza Martínez, 2011); Territorios y recursos naturales: el saqueo versus el buen Vivir (Broederlijk, 2008); Salvando la naturaleza: pueblos indígenas y ambientes (Colchester, 1995); "El mundo de la selva" (Descola, 1996); GAIA: la tierra inteligente (Devereux, Steele y Kubrin, 1991); El mito moderno de la naturaleza intocada (Diegues, 2000) y "Las preocupaciones por la relación naturaleza-sociedad. Ideas y teorías en los siglos XIX y XX. Una primera aproximación" (Galafassi, 2001).
}

Campos en Ciencias Sociales

ISSN: 2339-3688 | e-ISSN: 2500-6681 | DOI: https://doi.org/10.15332/25394363

Vol. 9 N. ${ }^{\circ} 1$ | enero-junio de 2021 
modernidad de alguna manera estaría influyendo en las maneras de vincularse con la pachamama" (2016, p. 201), al punto que se van dejando de lado viejas prácticas que consideraban el respeto hacia la misma(entendido como "ofrecer mi cariño") ${ }^{3}$ como algo imprescindible. $Y$ es que "el respeto implica tener la información necesaria, leer e interpretar adecuadamente esa información para actuar correctamente y, por ello, no torcer el sentido de la relación con la naturaleza, que siempre está al servicio de los seres vivientes y también del ser humano" (2016, p. 2).

En el contexto de lo anterior, se puede afirmar que el origen del buen vivir como concepto no se produjo en las mismas culturas indígenas, sino que fue traducido e interpretado por intelectuales que buscaban alternativas para el desarrollismo occidental. Buscaban incentivar una relación armónica entre la naturaleza y los seres humanos a partir de la cosmovisión andina. No se trata de aplicar la cosmovisión indígena exactamente, sino reinterpretarlas para poder resolver conflictos sociales en las planificaciones estatales.

Desde esta perspectiva, el término buen vivir encierra las búsquedas de una alternativa al modelo neoliberal de desarrollo occidental que ha sido impuesto en América Latina. El buen vivir aparece, así, como la opción utilizada para conseguir otra manera de ser y estar en el mundo, que no resulte perjudicial y que pueda realmente solucionar los problemas que se dan en tal coyuntura.

Este término no es del todo popular entre las comunidades indígenas, debido a que ha terminado por convertirse en un discurso político de Estado, que, al contrario de lo originariamente querido, desconoce y hasta desautoriza las transformaciones culturales y logros políticos obtenidos por

\footnotetext{
3 "El cariño no puede ser retribuido, es el acto más simple de donación que expresa el desprendimiento de algo que tiene y que no significa una inversión o entrega con alguna intensión. La donación es eso: la entrega gratuita al otro de aquello que le puede gustar, sin que esto signifique necesariamente una obligación entre las partes" (Mujica 2016, p. 205).
} 
los pueblos indígenas. En otras palabras, nos hallamos ante la paradoja de que el discurso sobre el buen vivir, que nació del calor de los movimientos sociales indígenas se haya convertido en una razón de Estado, y, por tanto, desarticuladora del poder popular que se consolidó en la década de 1990 en Bolivia y Ecuador.

Ahora, dicho discurso es promovido y utilizado por la esfera pública letrada y la esfera pública internacional para abordar los temas de desarrollo,

[...] se trata de una armonización balanceada entre los componentes materiales y espirituales de la vida, lo que además solo es posible en un contexto comunitario que sea al mismo tiempo social y ecológico, [...] una relación cooperativa de convivencia en la cual la idea de bienestar no está referida solamente a los seres humanos, sino también a los productos de la tierra, al ganado y a la Naturaleza como un todo, [...] el clásico "dualismo occidental moderno" que opone Naturaleza y sociedad queda desvanecido en esta perspectiva, pues en el ayllu lo social y lo natural no son separables. (Mella, 2015, pp. 282-283).

Si bien el buen vivir ha tenido variaciones según el contexto en el que se aplica o según el punto de vista en el que está ubicado el observador, la realidad es que la noción actual no fue asociada a sumak kawsay o a suma qamaña antes del año 2000. No se han encontrado referencias a dicho término, ya sea en escritos antropológicos, filosóficos, teológicos o económicos, con respecto al mundo indígena desde antes de ese año. Es desde el 2001 que se empiezan a registrar importantes contribuciones literarias sobre esos conceptos.

Bajo esta concepción, se deben tener en cuenta todos los elementos que conforman la Pacha. En la cosmovisión andina, debe haber una relación de complementariedad, correspondencia, movimiento cíclico del tiempo y reciprocidad. Se trata de que se dé, además de la armonía entre los seres, una adecuada convivencia intercultural, intergeneracional e interbiótica. 
La concepción que se tiene del buen vivir está basada principalmente en lo siguiente: un crecimiento sin límites no puede ser beneficioso para todos; si bien somos diversos, todos somos iguales, por lo que no debe haber un vivir "mejor" en el que personas se vean perjudicadas por el progreso del otro. De ahí, la necesidad de que la complementariedad y la solidaridad sean llevadas a promover una calidad de vida; la ayuda mutua entre los seres es lo que alimenta al buen vivir, no debe haber egoísmo; la reciprocidad y solidaridad son componentes fundamentales en la concepción andina de la vida. Estas incluso van más allá de la relación entre humanos, se extienden a todo el entorno natural, incluyendo animales, plantas e, incluso, espacios geográficos, como las montañas, lagos, ríos, etc.

El buen vivir visto desde una perspectiva ideológico-política busca que las personas puedan emanciparse, que potencien sus libertades, capacidades, oportunidades y potencialidades, para que puedan alcanzar metas que permitan el desarrollo tanto de su comunidad como de ellos mismos. Implica también el aprender a valorar las diversas identidades culturales y los elementos que ofrece el mundo sin tener la necesidad de dominar al otro o apropiarse de lo que es deseable.

“Crecemos" es, tal vez, una buena traducción para "Desarrollo", que los aymara no pueden [...] entender desde su visión orgánica y ecológica de la realidad. "Convivencia" es una palabra muy expresiva de cómo entienden las interrelaciones con su entorno, entendido como poblado por seres vivos; efectivamente, los aymara se saben parte de una comunidad biótica (Medina, 2011, p. 65).

Para poder comprender el concepto de desarrollo, estos pueblos necesitan establecerlo en un tiempo-espacio una pacha y es a ello a lo que llaman qama; 
[...] el espacio-tiempo de la Qamaña es algo vivo, compuesto por seres vivos y habitado por seres vivos. Así, para los aymaras, el subsuelo, el sueño, el agua, el aire, las montañas no solo que están vivos, sino que son, además, los espacio-tiempos en que "los seres espirituales están latentes"; los ecosistemas mismos: altiplano, valles, yungas son organismos vivos; las plantas, tanto cultivadas como silvestres, los animales, tanto salvajes como domesticados, son seres vivos. (Medina 2011, p. 59)

Todos aquellos seres vivos se encuentran conviviendo y compartiendo, ya sea con otros individuos, con su familia o con una comunidad humana. La visión andina es una en la que la solidaridad predomina y las personas siempre tienen en cuenta tanto a su familia 4 como a su comunidad, lo cual se opone a otros modelos de pensamiento occidentales en los cuales hay un evidente individualismo y las personas están orientadas según su interés personal.

El bienestar de la gente es indisociable del bienestar de la tierra, las plantas y los animales. El Qamaña, administrador del bienestar, tiene que relacionar y hacer interactuar a los comuneros con el espíritu de los animales, los vegetales, la tierra, el agua, las montañas, el cosmos. (Medina, 2011, p. 68)

Con ello, "un primer significado de Qamaña es: trama de vida donde la mutua interconectividad genera bienestar" (Medina, 2001 p. 60). Dicho de otro modo, es la existencia de vida en un espacio donde está establecido el bienestar. Tal bienestar no se reduce a los seres humanos, sino que implica también a todo ser puesto que se trata de llegar a un equilibrio bioesférico, un equilibrio desde donde se produzca bienestar.

\footnotetext{
${ }^{4}$ Es un trato afectuoso no solo con los humanos o seres sintientes, sino aun con las plantas (Regina, 1994).
} 
El buen vivir pone un énfasis en la importancia que tiene proteger la naturaleza y en la necesidad de que prime en todo momento la solidaridad. También, considera que se debe profundizar en la democracia, promoviendo así los derechos y garantías sociales. Sin embargo, este planteamiento nacido e inspirado por el modo de vida milenario de los andes difiere mucho del anterior. En la cosmovisión andina, por ejemplo, no se considera que el tiempo sea lineal y progresivo, por el contrario, se ve al tiempo como una espiral cíclica.

De este modo, se da siempre la posibilidad de mirar al pasado y "retroceder", si es necesario, para poder seguir un mejor camino. Ahí se encuentra una de las principales diferencias entre el desarrollo contemporáneo y la idea de desarrollo que tienen las culturas andinas. Es así como, para el hombre del Ande -al contrario del hombre occidental moderno-, el futuro se encuentra atrás, mientras que el pasado está delante, ello refiere a que caminan hacia el futuro de espaldas, mirando siempre al pasado y sin conocer lo que se encuentra en el futuro. A partir de ello aparece la noción de una "utopía retrospectiva", donde se busca recuperar el pasado inconcluso, para poder tener un mejor futuro, al encontrar alternativas sólidas y sostenibles que no vayan en contra de la naturaleza, las futuras generaciones o la humanidad. Es de este modo que se concibe el buen vivir amerindio, que tiene un impacto sobre las estructuras sociales, culturales, económicas y políticas y es una alternativa a la noción de progreso que se ha intentado globalizar o universalizar.

Cabe a la sociedad asumir un sentido de responsabilidad frente a las futuras generaciones, junto con reconocer ciertos derechos a la naturaleza que serían independientes de la utilidad práctica que le pueden asignar cada uno de los individuos, [...] insiste en la necesidad de introducir una serie de regulaciones destinadas, por un lado, a salvaguardar la naturaleza 
y, por otro, evitar y reducir una serie de riesgos sociales. (Avendaño, 2010, p. 559)

El suma qamaña o allin kawsay está relacionado íntimamente con la "vida", con una visión cosmocéntrica y holista, a diferencia de la visión de las propuestas occidentales dominantes modernas o contemporáneas. Ello quiere decir que los "entes inertes" tienen un valor importante para los indígenas. Mujica , al hablar de pacha, por ejemplo, la cataloga como "una categoría englobante [que] abarca 'todo lo que está a la vista' o aquello que puedo sentir que pasa' y 'lo que me envuelve’, y ‘da a una persona identidad propia"' (2016, pp. 211-212). Con ello es que, consideran, debe haber una relación de complementariedad y reciprocidad, entre todos los elementos y entes que se encuentran en el mundo, de ahí proviene la armonía y equilibrio del cosmos, en palabras de Mujica:

[...] la pacha se hace compleja en la medida que asigna el espacio con todos sus matices y también indica el tiempo en sus diversas modalidades y segmentaciones. A esto hay que añadir las concepciones intersubjetivas que tiene el término pacha para indicar no solo las identidades de las personas, sino la identidad misma del individuo cuando se reconoce que la pacha tiene tanto chawpi como uku y es como una matriz de la identidad del ser humano, que hoy en día se podría identificar con los derechos humanos. (Mujica, 2016, p. 235)

De ahí, sí podemos entender a pacha como espacio, como tiempo y como subjetividad. Se trata de una "ontología relacional" donde todo se encuentra vinculado: el pasado con el futuro, los animales con las plantas y los hombres, la naturaleza con lo artificial, la vida con la muerte, etc. Hay una clara diferencia entre la visión andina y la visión individualista en la cual se encuentra un fuerte antropocentrismo.

El "Vivir Bien" amerindio mide la "bondad" de cada elemento por la "bondad" del todo, es decir: el "vivir" depende fundamentalmente del 
"con-vivir" en un sentido antropológico, ecológico (o ecosófico) y cósmico.

No se puede -en sentido estricto- hablar de que alguien tiene "buena vida" (un tercio de la humanidad), si otros/as viven en la miseria o son pisoteados/as por los demás. Por tanto, el "Vivir Bien" no aspira a una "mejor vida", porque en un mundo finito y limitado en cuanto a recursos, espacio y tiempo, el incremento de la calidad de vida de algunos/as conlleva al deterioro de la calidad de vida de otros/as. (Estermann, 2012, p. 14)

Es bajo esta ley que se rige el desarrollo contemporáneo, en un individualismo que resulta perjudicial para una mayoría de la población. Por el contrario, el ideal andino del buen vivir abarca incluso a la naturaleza humana y a todo el cosmos, entre lo que se incluye tanto al mundo espiritual como al mundo religioso. No puede haber un equilibrio entre los seres humanos, si con el "progreso" se genera una destrucción ecológica y transgeneracional. Por ello es por lo que el buen vivir busca que realmente se produzca una armonía entre los seres humanos, su entorno y el mundo espiritual, teniendo también en cuenta a las futuras generaciones ${ }^{5}$.

Esto, sin embargo, no implica que el buen vivir se constituya como un discurso monolítico y hegemónico. Al contrario, es perfectamente consciente de todas sus fisuras y contradicciones. No se trata de una idealización del pasado, sino más bien de sacar de un mundo de vida concreto ciertos valores y formas de vida, que nos puedan servir para entrar en diálogo intercultural con el mundo constituido por la modernidad occidental.

\footnotetext{
${ }^{5}$ Mujica plantea al pukllay como una propuesta ética para el runa andino consciente de que la acción individual será eficaz si entra en concordancia con la acción colectiva, logrando articular sus capacidades $y$, al mismo tiempo, generando un movimiento que le permita hacer pukllay. El pukllay es "la conjunción de dos elementos diversos en una interacción", donde queda claro que lo fundamental no solo es el movimiento y el cambio constante, sino la interacción y articulación del contacto con el otro (Mujica, 2016, pp. 339-341).
} 
No se trata, entonces, de idealizar lo que fueron las sociedades precolombinas, ni de ignorar las contradicciones existentes hoy día en los pueblos autóctonos, tal como existen en todos los grupos humanos. Las relaciones de autoridad, el estatuto de la mujer [y] el respeto a la vida humana no fueron siempre ejemplares en estos grupos sociales y el carácter que hoy día llamaríamos "imperialista" de los reinados inca y azteca no se puede negar. La divinización del inca, por ejemplo, fue una señal evidente del deterioro de las relaciones tributarias entre les entidades locales y el poder central. Hoy en día, las organizaciones indígenas tienen sus conflictos de pensamiento y de poder, sus alianzas dudosas [...] con poderes políticos o económicos, sus diferencias ideológicas que van desde el neoliberalismo hasta el socialismo. Es decir, son grupos sociales como los demás, con sus historias, sus sueños, sus vidas propias. Es por eso que merecen un reconocimiento social, luego de medio milenio de opresión y destrucción. Recordar el sumak kawsai es hacer revivir la "utopía práctica" de sus tradiciones, que orientó la ética colectiva y la esperanza del actuar de sus comunidades. Es el aporte específico que los pueblos originarios de Abya Yala ofrecen a la construcción de una nueva civilización. Lo hacen con su cosmovisión propia, elemento importante de una multiculturalidad que puede convertirse en interculturalidad. (Houtart, 2014, p. 104).

Se podría decir que en el modelo dominante en Occidente los últimos 400 años sobresalen la actitud económica y la política, las cuales están basadas en principios que son destructivos tanto para la naturaleza como para las futuras generaciones, puesto que se les da prioridad a los bienes de lujo sobre los bienes que son de primera necesidad y los valores espirituales y éticos. Además, esta visión busca siempre el crecimiento ilimitado, sin considerar que aquellos recursos naturales que utiliza para conseguir su objetivo no son ilimitados ni, en algunos casos, renovables.

Por el contrario, para esta visión que presentamos, el "progreso" no está asociado a la acumulación de bienes materiales o simbólicos, ni en el 
incremento de las ganancias de una empresa, más bien busca que se dé una distribución justa y equitativa de las riquezas que existen, siendo conscientes de que debe haber un uso prudente, ya que estas no son ilimitadas.

Sin embargo, esto sería caer en una dicotomía insalvable e inconmensurable. Si la crítica a la noción occidental moderna del desarrollo del sumak kawsay quiere tener alguna incidencia en la política o el debate académico, entonces no puede renunciar al diálogo intercultural. No se trata solo de confrontar sino de avanzar hacia un entendimiento racional, entendiendo a la razón en su más amplio sentido relacional. La vía de la interculturalidad saca a la luz estas otras alternativas, vitales para ingresar en un diálogo que no desdeñe las condiciones históricas de las relaciones de poder. En ese sentido,

[...] lo fundamental en la transformación del modelo de desarrollo radica en una nueva forma de concebir lo productivo,[...] no se trata solo de disminuir la influencia del mercado y del sector privado sino de cambiar la visión política de quienes deciden lo que se produce y consume. Para efectos de la organización productiva de una sociedad, y considerando también la relación entre los países, añade el principio de “complementariedad". Este principio se manifiesta - de preferencia- en las relaciones de intercambio, permitiendo "eliminar injusticias y crear otros equilibrios”. (Avendaño. 2010, p. 559)

No puede haber un "progreso" o "desarrollo", si hay personas que se ven perjudicadas con ello, con tal de que unos pocos puedan obtener todos los beneficios. El crecimiento económico no debe estar dirigido a las minorías privilegiadas. No es bajo el consumismo desenfrenado que se alcanza el "progreso", este solo nos dirige al deterioro de los recursos naturales y al desequilibrio cósmico. La noción del buen vivir presenta a un modelo civilizatorio como alternativa del modelo dominante de la modernidad 
occidental, que solo ha conseguido decadencia y agotamiento para grandes sectores de la humanidad, evidenciando así que no es sostenible.

Una de las convicciones de la sabiduría indígena andina es que todo tiene que ver con todo, es decir que el "desarrollo" de una parte de la humanidad tiene que ver con el subdesarrollo de la otra parte. La tierra es (y el universo en su totalidad) un sistema limitado que no permite un "crecimiento ilimitado", que solo se da en el caso del cáncer, [...] el capitalismo aún vigente, en su agonía, es un sistema sumamente cancerígeno que produce metástasis lejos del origen de la enfermedad. [...] Una economía realmente sustentable y sostenible en términos de la sobrevivencia de la humanidad y de la vida en general, es decir, una economía compatible con la totalidad de la humanidad, la naturaleza, el mundo espiritual y las futuras generaciones, debe renunciar a la ideología del "crecimiento" como mundo base del "vivir bien", a la especulación bursátil y el capital improductivo ficticio. (Estermann, 2012, p. 15)

Con el buen vivir no se espera sustituir al mercado por el Estado, sino que se espera que pueda haber una relación dinámica y constructiva entre el Estado, la sociedad y el mercado, consiguiendo así un equilibrio entre ellos. Se espera que la actividad económica no esté en función del beneficio individual, sino que quienes se han visto excluidos por el neoliberalismo tengan ahora la oportunidad de ser beneficiados. Por ello, es fundamental "establecer una relación armónica entre sociedad y naturaleza" (Avendaño, 2010, p. 559).

El buen vivir no es tan solo la expresión de una cosmovisión única o una concepción determinada sobre el desarrollo, el progreso y la organización de la sociedad, sino que "implica una ciudadanía activa y la capacidad de emprender acciones en función del respeto de la biodiversidad" (Avendaño, 2010, p. 560). El que este concepto sea aplicado a las sociedades supone un proyecto donde se produce un cambio de paradigma con respecto a cómo se 
concibe el desarrollo, la participación política de los individuos y el rol que debe cumplir el Estado para su funcionamiento adecuado.

\section{El buen vivir en la filosofía indígena: la naturaleza en la mira del debate}

Para poder abordar la importancia que tiene la naturaleza como instrumento crítico del desarrollo y, con ello, la preservación y cuidado de los recursos naturales, proponemos desarrollar el buen vivir desde la filosofía indígena. El reconocer esta visión no significa que se pretenda detener el desarrollo o los avances tecnológicos que se han dado, tampoco implica negar los grandes aportes del pensamiento de la humanidad que están orientados hacia un mundo más equilibrado y armónico, tal y como lo está la filosofía del buen vivir. Es por ello que se debe establecer un diálogo constante y constructivo de saberes y conocimientos ancestrales con lo más desarrollado del pensamiento universal.

En la cosmovisión andina no se considera como existente un estado subdesarrollado que sea necesario superar. Asimismo, no hay necesidad de destruir las relaciones sociales y el equilibrio con la naturaleza con el objetivo de llegar a un estado de desarrollo "mejor". Lo que ocurre es que, a diferencia de la visión occidental, en la concepción indígena la pobreza no está relacionada con la ausencia de bienes materiales, de igual modo que la riqueza no se alcanza al acumular tales bienes.

Debido a que las acciones humanas que fomentan el buen vivir están determinadas por diversos elementos en este mundo de la vida, los bienes materiales no son lo más relevante para mantener un equilibrio cósmico. Hay valores que se deben considerar, ya sea el conocimiento, la ética, los códigos de conductas espirituales, el reconocimiento a nivel social y cultural o la relación con la naturaleza y sociedad. 
El Buen Vivir aparece como una categoría en la filosofía de vida de las sociedades indígenas ancestrales, pero que ha perdido terreno por efecto de las prácticas y mensajes de la modernidad occidental, así como por efecto de la colonialidad del poder. Su aporte, sin embargo, sin llegar de ninguna manera a una equivocada idealización del modo de vida indígena, nos invita a asumir otros 'saberes'y otras prácticas, en este caso, de los pueblos y nacionalidades tradicionalmente marginadas. (Acosta, 2010, p. 12)

Por otra parte, la noción del buen vivir que tienen los pueblos indígenas implica una estrecha relación con la naturaleza. Todos los principios de este término establecen una relación entre el ser humano y su entorno. Si bien, para Occidente, la naturaleza es considerada como materia prima, un medio de producción y transformación que se encuentra a completa disposición del hombre, para los pueblos andinos es lo contrario. La naturaleza tiene vida y debe ser respetada y cuidada por los mismos seres humanos. No se trata de un objeto explotable y manipulable que no posee derecho ni libertad.

Para el espíritu moderno de Occidente, la naturaleza se vuelve recursos naturales (agua, tierra, aire, minerales, hidrocarburos, etc.), que son la materia prima para el proceso de producción y transformaciones de bienes de consumo. El ser humano, por considerarse "superior", se siente "dueño" y destinatario único de estas riquezas. (Estermann, 2011a, p. 6)

Esta visión que subyace a la cultura andina sirve también como base de la crítica al modelo acumulativo del desarrollo capitalista. Desde la perspectiva del buen vivir, según los pueblos andinos, la acumulación de bienes materiales de modo mecánico e interminable no tiene un futuro. Los recursos naturales no pueden ser entendidos como una condición para poder lograr un desarrollo económico sustentable, lo que vemos evidenciado en los constantes problemas de tipo ecológico y, además, 
de exclusión y pobreza extrema, que este modelo no ha sabido resolver adecuadamente. Además, desde la perspectiva del buen vivir, lo humano debe realizarse siempre en comunidad, para que, de este modo, los sujetos estén con y en función de otros seres humanos, sin buscar dominar la naturaleza, ya que los mismos seres humanos son parte de ella.

[...] desde los albores de la humanidad el miedo a los impredecibles elementos de la Naturaleza estuvo presente en la vida cotidiana. Poco a poco la ancestral y difícil lucha por sobrevivir se fue transformando en un desesperado esfuerzo por dominar las fuerzas de la naturaleza. Se llegó a querer ver al ser humano por fuera de la naturaleza, incluso al definir la naturaleza sin considerar a la humanidad como parte integral de la misma. Así se abrió la puerta para dominarla y manipularla. [...] Se separó al ser humano de la naturaleza, transformándola a ésta en una fuente de negocios aparentemente inagotable. (Acosta, 2010, p. 17)

Para poder luchar contra aquella visión, se requiere de una ética nueva que permita organizar la vida, se "precisa reconocer los límites biofísicos de las actividades desarrolladas por los humanos. La realidad nos demuestra hasta la saciedad que la Naturaleza tiene límites" (Acosta, 2010, p. 18). Tales límites son alcanzados por la mayoría de estilos de vida antropocéntricos que privilegian la búsqueda de una acumulación de capital, estos estilos de vida se hacen cada vez más notorios e insostenibles.

La labor a realizar puede resultar compleja, pero es fundamentalmente simple. Se trata de conseguir el reencuentro entre los seres humanos y la naturaleza, entendiendo que ellos mismos son parte de ella. Una de las principales tareas es la de desmercantilizar la naturaleza. Los objetivos económicos deben ser realizados según el funcionamiento de los sistemas naturales, solo de este modo se podrá acabar con su explotación indiscriminada. Se debe, además, mantener en todo momento el respeto 
a la dignidad humana y mejorar la calidad de vida de las personas, teniendo en cuenta que el desarrollo económico no es un fin, sino un medio.
Dotarle de Derechos a la Naturaleza significa, entonces, alentar políticamente su paso de objeto a sujeto, como parte de un proceso centenario de ampliación de los sujetos del derecho. A lo largo de la historia legal, cada ampliación de los derechos fue anteriormente impensable. La emancipación de los esclavos o la extensión de los derechos a los afroamericanos, a las mujeres y a los niños y niñas fueron una vez rechazadas por ser consideradas como un absurdo. (Acosta, 2010, p. 18)

Esta perspectiva, que para los hombres modernos de occidente puede parecer extraña y hasta irracional, es completamente común y aceptable para un poblador del ande. La modernidad, que desde sus albores establece una separación dualista entre el hombre y la naturaleza, no puede comprender la visión relacional del cosmos que pueden tener otros mundos de vida distintos al suyo. Por eso, lo que se estaría haciendo, al otorgarle derechos a la naturaleza, es reafirmar su derecho a la existencia. Para lograr ello se requiere de un esfuerzo político que establezca la importancia del cuidado del entorno y, con ello, de la naturaleza.

Una visión relacional y empática del cosmos, como la del buen vivir, asume que todo influye en todo, y esto permite ir más allá de la relacionalidad mecánica, causal o lógica, incorporando una base de concordancia en la que la ambigüedad, la potencia y la precariedad de los nudos relacionales que constituyen los entes exigen atención y cuidado. Enraizada en esta dimensión ritual del saber y de la vida, persiste el mundo de la vida andino; por ejemplo, en ámbitos como la medicina, la cosmología, la climatología, o la biología, entre otros, de un potencial menospreciado (cuando no ignorado) por un sistema que se erige a sí mismo como el único posible. 
Se requiere, además, de que el tránsito sea sostenido y plural, en escenarios donde se pueda producir un ordenamiento con respecto a la sociedad y la economía que mantengan la integridad de los procesos naturales. Es decir, se trata de llegar a mejores métodos y modificar las estructuras sociales, económicas, políticas y culturales, siempre teniendo en cuenta la preservación de la biodiversidad en el planeta. Con todo ello, se podrían mejorar las condiciones de vida para todos los seres que habitan el planeta, en vez de seguir con los sistemas actuales donde tan solo unos pocos son los beneficiados.

La propuesta de otorgarle derechos a la naturaleza surge a partir de la crisis en la que se encuentra el mundo en la actualidad, al optar por seguir con un modelo depredador en el cual los seres humanos siguen luchando contra la naturaleza. Se debe romper con la idea de que el bienestar y riqueza provienen de la acumulación de bienes materiales, como, también, de que el desarrollo y el progreso son ilimitados. Por ello, el consumo y el crecimiento deben ser moderados. Es necesario reconocer que los instrumentos y conocimientos actuales tienen una visión colonial y eurocéntrica que no es la adecuada.

Dado el carácter contractualista de su ética y derecho, se entiende que el hombre moderno no tiene obligación alguna con sus antepasados ni, menos aún, con los humanos y criaturas que están por venir y que tal vez nunca sean: no cabe contrato alguno con lo que no es. Aquella sensibilidad alienta su conducta predatoria. Esto no ocurre en el mundo de la vida andino: en él, la comunidad y el sentido de respeto que la sustenta abarcan a los antepasados y a los que vendrán. Todos son sujetos de derecho y obligación. También, se incluye en esto a las deidades y al entorno natural. En tal sentido, esta ontología sí posibilita hablar de los derechos de las futuras generaciones, de los antepasados y, por supuesto, de la naturaleza. 
Tal vez a través del ideal que, en estas circunstancias, encarna el buen vivir, se pueda vencer y erradicar esta visión monolítica del desarrollo capitalista, que resulta tan perjudicial. A partir de lo que se propone en el buen vivir, se dejaría la visión colonial y eurocéntrica, para, así, adoptar medidas que puedan llevar a un verdadero desarrollo diferente al actual. Que la naturaleza sea sujeto de derechos permite que se mantenga un equilibrio y una armonía entre los seres humanos y lo que los rodea.

Para ello, se deben diferenciar los derechos humanos y los derechos de la naturaleza. Por un lado, en los derechos humanos, quien se encuentra en el centro del asunto es el hombre, por lo que se trataría de una visión antropocéntrica. Los derechos de primera y segunda generación, es decir, los políticos y sociales, son tomados en cuenta por el Estado como parte de una visión individualista de la ciudadanía. En los derechos de tercera generación, es decir, ambientales y culturales, se reconoce el derecho de que las personas tengan condiciones sociales equitativas y un medio ambiente no contaminado y saludable. Se intenta eliminar tanto la pobreza como el deterioro ambiental, que afectan la calidad de vida de los seres humanos. Con ello se debe considerar que:

Los derechos de primera generación se enmarcan en la visión clásica de la justicia: imparcialidad ante la ley, garantías ciudadanas, etc. Para cristalizar los derechos económicos y sociales se da paso a la justicia redistributiva o justicia social, orientada a resolver la pobreza. Los derechos de tercera generación configuran, además, la justicia ambiental, que atiende sobre todo demandas de grupos pobres y marginados en defensa de la calidad de sus condiciones de vida afectada por destrozos ambientales. En estos casos, cuando hay daños ambientales, lo seres humanos pueden ser indemnizados, reparados y/o recompensados. (Acosta, 2010, p. 19) 
Por otro lado, en lo que refiere a los derechos de la naturaleza, el centro no es solo el ser humano, sino la naturaleza, que, de igual modo, también incluye al ser humano. Se trataría, de este modo, de una visión biocéntrica. Con estos derechos, se quiere decir que la naturaleza tiene un valor propio, independientemente de la utilidad que le otorgue el hombre. Con estos derechos no se intenta que la naturaleza sea intocable o que no se pueda producir a partir de ella. Más bien, lo que se quiere es que se mantengan y respeten los sistemas naturales de vida, estos derechos tienen en cuenta a los ecosistemas y a las colectividades.

Con estos derechos, la justicia ecológica busca la persistencia y sobrevivencia de las especies, junto a sus ecosistemas, entendiéndolos como redes de vida. Es una justicia que se diferencia de la justicia ambiental, pues no pretende indemnizar a los seres humanos, sino a la misma naturaleza, a través de la restauración de los ecosistemas que han sido afectados. Lo ideal es que ambas justicias actúen al mismo tiempo, con lo que se daría la justicia ambiental para las personas y la justicia ecológica para la naturaleza.

Los derechos de la Naturaleza necesitan y a la vez originan otro tipo de definición de ciudadanía, que se construye en lo social pero también en lo ambiental. Este tipo de ciudadanías es plural, ya que depende de las historias y de los ambientes, acoge criterios de justicia ecológica que superan la visión tradicional de justicia. De los Derechos de la Naturaleza se derivan decisiones trascendentales. Uno clave tiene que ver con procesos de desmercantilización de la Naturaleza, como han sido la privatización del agua o la introducción de criterios mercantiles para comercializar los servicios ambientales. (Acosta, 2010, p. 20)

Con ello, se evidencia la importancia del cambio de visión, para lograr que todos los seres que habitan el planeta tengan una mejor vida. Además, no se estaría "favoreciendo" a la naturaleza sobre los seres humanos, sino que, al 
proteger a la naturaleza y otorgarle derechos, se estaría haciendo lo mismo con la vida humana.

A lo que apunta la visión del buen vivir es a servir como base de un Estado intercultural y plurinacional que tenga una relación estrecha con los derechos de la naturaleza, los cuales se interrelacionan con los derechos humanos. Con ello, se podrían formar sociedades sustentables, a través de las ciudadanías plurales, que tengan en cuenta la importancia de la naturaleza.

\section{Referencias}

Acosta, A. (2012). Buen Vivir. Sumak Kawsay. Una oportunidad para imaginar otros mundos. Editorial Abya Yala.

Acosta, A. (2011). Riesgos y amenazas para el Buen Vivir. Revista Ecuador Debate, (84), 555 .

Acosta, A. (2010). El Buen Vivir en el camino del post-desarrollo. Una lectura desde la Constitución de Montecristi. Fundación Friedrich Ebert; FES-ILDIS.

Acosta, A. (2009). Derechos de la naturaleza: el futuro es ahora. Editorial Abya-Yala.

Acosta, A. (2008). La naturaleza como sujeto de derechos. Peripecias, (87).

Acosta, A. y Martínez, E. (2011) (Comp). La naturaleza con derechos: de la filosofía a la política. Editorial Abya Yala.

Acosta, A. y Martínez, E. (2009). (Comp). El buen vivir: una vía para el desarrollo. Editorial AbyaYala.

Avendaño, O. (2010). El buen vivir. Una vía para el desarrollo. Polis (Santiago), 9(25), 557561. https://doi.org/10.4067/So718-65682010000100031

Broederlijk, D. (2008). Territorios y recursos naturales: el saqueo versus el buen vivir.

ALAI.

Colchester, M. (1995). Salvando la naturaleza: pueblos indígenas y ambientes. UNRISD.

Devereux, P., Steele, J. y Kubrin, D. (1991). GAIA: la tierra inteligente. Ediciones Martínez Roca.

Campos en Ciencias Sociales

ISSN: 2339-3688 | e-ISSN: 2500-6681 | DOI: https://doi.org/10.15332/25394363

Vol. 9 N.o 1 | enero-junio de 2021 
Diegues, A. C. (2000). El mito moderno de la naturaleza intocada. Editorial Abya-Yala.

Escobar, A. (2010). Una Minga para el postdesarrollo. América en movimiento, (445), 26-30.

Escobar, A. (2000). El lugar de la naturaleza y la naturaleza del lugar: ¿globalización o postdesarrollo? En E. Lander (Ed..), La colonialidad del saber: eurocentrismo y ciencias sociales. Perspectivas latinoamericanas (pp. 155-201). FACES;

UVCIESALC.

Escobar, A. (1996). La invención del desarrollo. Construcción y deconstrucción del desarrollo. Ediciones Norma.

Espinoza, R. (2010, 17 de febrero). Perú: el Buen Vivir, alternativa indígena a la crisis global de la civilización. Biodiversidad La.

https://www.biodiversidadla.org/Documentos/Peru el Buen Vivir alternativa in digena a la crisis global de la civilizacion occidental

Estermann, J. (2012), Crisis civilizatoria y Vivir Bien. Una crítica filosófica del modelo capitalista desde el allin kawsay/suma qamaña andino. Polis. Revista Latinoamericana, 11(33), 149-174.

Estermann, J. (2011a). Crecimiento cancerígeno versus el Vivir Bien. La concepción andina indígena de una vida sostenible como alternativa al desarrollismo occidental. https://gilbertobonilla.files.wordpress.com/2011/02/ponencia-de-josefestermann-crecimiento-canceric3acgeno-versus-el-vivir-bien.pdf

Estermann, J. (2011b). 'Vivir bien’ como utopía política: La concepción andina del “vivir bien" (suma qamaña/allin kawsay) y su aplicación en el socialismo democrático en Bolivia. En Museo de Etnografía y Folclore (Ed.), Reunión anual del Museo de Etnografía y Folclore 2010: el vivir bien, (pp. 517-533). Museo de Etnografía y Folclore.

Estermann, J. (2006). Filosofía andina: sabiduría indígena para un mundo nuevo. ISEAT. http://casadelcorregidor.pe/colaboraciones/ biblio Josef Estermann.php

Esteva, G. (2009). Más allá del desarrollo: la buena vida. América en movimiento, (445), $1-5$.

Fernández, B., Pardo, L. y Salamanca, K. (2014). El buen vivir en Ecuador: ¿marketing político o proyecto en disputa? Un diálogo con Alberto Acosta. Iconos, Revista de ciencias sociales, (48), 101-117.

Campos en Ciencias Sociales

ISSN: 2339-3688 | e-ISSN: 2500-6681 | DOI: https://doi.org/10.15332/25394363

Vol. 9 N. ${ }^{\circ} 1$ | enero-junio de 2021 
Galafassi, G. P. (2001). Las preocupaciones por la relación naturaleza-sociedad. Ideas y teorías en los siglos XIX y XX. Una primera aproximación. Theomai, (3). http://www.uacm.kirj.redalyc.redalyc.org/articulo.oa?id=12400311

Gudynas, E. (2011). Buen Vivir: germinando alternativas al desarrollo. Separata Destaques del Foro Social Mundial 2011. América Latina en Movimiento (ALAI), (462). https://www.alainet.org/es/active/48052

Gudynas, E. (2009a). El mandato ecológico. Derechos de la naturaleza y políticas ambientales en la nueva Constitución. Editorial Abya Yala.

Gudynas, E. (2009b). Diez tesis urgentes sobre el nuevo extractivismo. Contextos y demandas bajo el progresismo sudamericano actual. En CAAP y CLAES (Eds.), Extractivismo, política y sociedad (pp. 187-225). CAAP y CLAES.

Gudynas, E. (2004). Ecología, economía y ética del desarrollo sostenible. CLAES; Editorial Coscoroba.

Gudynas, E. y Acosta, A. (2011). El buen vivir o la disolución de la idea del progreso. En M. Rojas (Coord.), La medición del progreso y del bienestar. Propuesta desde América Latina (pp. 103-110). Foro Consultivo Científico y Tecnológico.

Medina, J. (2001). Suma Qamaña: la comprensión indígena de la buena vida. Federación de Asociaciones Municipales de Bolivia.

Mella, P. (2015). Ética del posdesarrollo. Ediciones Paulinas; Ediciones MSC; Instituto Filosófico Pedro Federico Bonó.

Mujica, L. (2016). Pachamama Kawsan: hacia una ecología andina. Fondo Editorial de la Pontificia Universidad Católica del Perú.

Prada, R. (2013). Ontología política del Sumak Kausay-Sumaj Qamaña. http://dinamicasmoleculares.webnode.es/news/potencia-existencia-y-plenitud

Yáñez Cossío, C. (2012). Pachamama, sumac causai y derechos de la naturaleza. Instituto Macac.

Campos en Ciencias Sociales

ISSN: 2339-3688 | e-ISSN: 2500-6681 | DOI: https://doi.org/10.15332/25394363

Vol. 9 N. ${ }^{\circ} 1$ | enero-junio de 2021 